\title{
Equating the State Unified and West African School Certificate Mathematics Examination Items
}

\author{
Adeyemo Emily Oluseyi \\ Department of Educational Foundations and Counselling \\ Faculty of Education \\ Obafemi Awolowo University, Ile-Ife \\ Nigeria
}

\begin{abstract}
The study determined the item parameters of the 2015 Unified Mathematics Examination and the WAEC Mathematics Examination Items. It also determined the comparability of the two Mathematics Examination items in terms of examinee's scores and item parameter. A survey research design was adopted for the study. The population for the study comprised 24,550 SSS 3. The study sample consisted of 360 students selected using multistage sampling techniques.. The research instruments used for this study were an adopted version of the Ekiti State 2015 Unified Examination and 2015 West Africa School Certificate Examination Mathematics items. The two instruments were administered on the study sample. Data collected were analyzed using paired sample t-test, Pearson Product Moment Coefficient and Linear Regression. The results showed that the difficulty index of the State Unified examination Mathematics items ranged from $11.34 \%$ to $50.00 \%$ and also the discrimination index ranged between -0.001 and 0.624. On the other hand, the difficulty index of WAEC Mathematics items ranged between $29.9 \%$ and $64.4 \%$ and the discrimination index ranged between 0.344 and 0.885 . The relationship in students' performance in the two examinations was significant $(t=4.664, p<0.05)$ and $(r=0.173, p=0.001)$. finally $(t=3.330, p=0.001) \quad$ The study concluded that the items were symmetrical.
\end{abstract}

Keywords:-Equating, Unified Examination, difficulty level, discrimination index

Teaching - learning activity cannot be fully achieved until the students are assessed. Assessment of students learning outcomes as intended is an attempt to collect a variety of continuous and comprehensive information about the process and outcomes of learning that have been achieved by the students through the teaching and learning activities, as the basis for determining the next steps. One of such techniques commonly used to measure this is a test.

Onunkwo (2002) described test as an instrument which can be utilized in detecting some qualities, traits, characteristics, attributes etc possessed by a person, an object or a thing while examination is a more formal way of a test that measure the knowledge of a student on a number of lessons. A test is otherwise known as examination. At the school level, educators conduct tests to measure students' understanding of specific contents or effective application of critical thinking skills. Such tests are used to measure or evaluate students' learning skill, level, growth and academic achievements at the end of an instructional period, end of course, semester or school year to know students strength and weakness. The promotion examination conducted at the end of the third term in schools is a type of examination that qualifies students to be promoted from one class to another. Some states in Nigeria designs a type of examination for their Senior Secondary School (SSS 2) two students to qualify them for promotion to SSS 3. This type of examination is called the State Unified Examination (SUE) in Ekiti state. The results of the test is expected to reflect the real academic situation of a student and it is also assumed that for a student to pass the examination, he/she would pass the Senior School Certificate Examination (SSCE) conducted by the West African Examination Council which the state government pay for.. However, students' performance in the (SSCE) has not been encouraging in the past years despites the fact that the category of students performed very well in the State Unified Examination. The insinuation from the public is that something can be done to enhance the performance of the students in external examination. Most students who passed the Sate Unified Examination and registered for the WASCE on the basis of their performance in the State Unified Examination still failed the SSCE . An important area which seemed to have been overlooked is the comparability of the items of these examinations in terms of their difficulty level and discrimination index. 
Through test item analysis, information about the goodness or otherwise of the items are obtained. The concern were whether the structure of test items were constructed according to syllabus?, whether the teachers has done the test item analysis that were used to evaluate the students grade? whether the test were good or bad based on the number of answers and the difficulty of items. This study aimed to find out if the Unified Examination actually prepared students for the SSCE examination while attempting to look for the quality of the State Unified and theWASC examination questions of 2014/2015 in terms of difficulty level, discriminating power and the pattern of answer distribution in determining whether the test can be called a qualified test or not. The aim of the study therefor is to carry out a comparative analysis of the WASC and the Ekiti State Unified (EKSU) Examinations items scores.

Ekiti state is among the states in Nigeria where the students' performance has not been encouraging in the external examinations in the past years. Majority of students that sat for the May/June West African Examinations Council (WAEC) have been recording poor results not only in the area of overall performance of students, but also in the core subjects like Mathematics and English Language. The results of candidate's performance in WAEC from previous years revealed a very poor level of performance compared to that of some other sates with outstanding percentages in the examination. The following is the performance record of Ekiti state with students who have a minimum of five credits including Mathematics and English language in WAEC for the past 10years (as released by the Test Development Division of the Examination WAEC) Lagos:) 20\% (2000), 25.3\% (2001), 21\% (2003), $18 \%$ (2004), 22\% (2005), 13\% (2006), 12\% (2007), 20\% (2008), 30\% (2009), $23 \%$ (2010)..

In a bid to reposition and improve the standard of education at all levels in Ekiti state, the Unified Examination for Senior Secondary School Two (SSS 2) was introduced. It is a common examination that cut across all SS2 classes in Ekiti State. The examination comes at the end of third term. It is only those students that pass the examination that are promoted to SS3 and are registered for the SSCE. The essence of the Unified Examination is to make the best selection of students out of the so many that sat for the examination to enjoy the state government free scholarship that registered them for SSCE. The minimum number of subjects a candidate can sit for is eight while the maximum is nine out of the total forty five subjects. Mathematics, English Language and Civic Education are compulsory. Credit grade in Mathematics and English Language is prerequisite for admission. Apart from the fact that Mathematics is compulsory, different researchers in the field of education have acknowledged the importance of Mathematics in scientific and technological developments. Mathematics allows scientists to communicate ideas using accepted terminology. The Mathematics questions conducted by the State Unified Examination Council and WAEC comprise of two parts. The first part is multiple choice, tagged Mathematics I and the second part is an essay test tagged Mathematics II. The past questions of both examinations showed that the two examining bodies pattern their questions the same way. This study seeks to find out how comparable the Mathematic items of both examinations are, in terms of the difficulty level and discriminating power and also to equate both examinations scores using linear test score equating.

Equating refers to a family of procedures for adjusting person location estimates that are on different metrics in order to place the estimates on a common metric (de Ayala,2009). Test equating method ensures that candidates are measured against the same criterion-referenced standard, regardless of the test administration they face. An examination meant to test the same area may vary in difficulty from administration to administration. Test equating accounts for these differences so that the same criterion-referenced standard can be used. The purpose of test equating is to place examination administrations on the same benchmark (or standard) scale.

The specific objectives of the study were to determine :-

(i) the item parameters of the EKSU Mathematics examination items

(ii) the item parameters of the WASC Mathematics examination items

(iii) the comparability of the two Mathematics examinations items in terms of examinee scores and item parameters using test equating method

\section{Methods}

The study adopted survey research design. This design was adopted in view of examining the extenvg $t$ of comparability of Mathematics tests administered by the examination bodies which made it possible to conclude that the scores yielded from different tests measuring the same construct were comparable to each other. The study population comprised all Senior Secondary School Three Students (SSS 3) in Ekiti State. There were 351 accredited secondary schools, 187 public secondary schools and 164 registered private secondary schools. 
The students' population consisted a total number of 24,550 with a total number of 11,300 boys and 13,250 girls as at the period of carrying out this study.(The statistics were collected from the Ministry of Education in Ekiti State). The study sample consisted of 360 students of SSS III selected using multistage sampling techniques from the three senatorial districts in the state, ( Ekiti Central, Ekiti East and Ekiti North). From each of the three senatorial districts in the state, two Local Government Areas (LGAs) were selected each using simple random sampling technique to make a total of six. From each of the two LGAs two schools were also selected randomly to make a total of 12 schools. From each school of the 12 schools selected, 30 Senior Secondary School three (SSS III) students were selected using simple random sampling techniques thereby making a total of 360 students used for the study sample. Two instruments were used for the study "Mathematics Achievement Test A (MAT A) and Mathematics Achievement Test B (MAT B). The instruments employed in this study were adopted version of the Ekiti State Unified Examination and WAEC Mathematics Objective sections. The Mathematics objective questions for both examinations were made up of 50 multiple-choice items and each item had four options lettered A - D. The students had covered a reasonable portion of the contents of the SSS III and WASC syllabuses and were preparing for public examinations. The areas the items covered were Mensuration, Algebraic Process, Plane Geometry, Trigonometry, Statistics and Probability, and Calculus. These items covered all the levels of cognition (comprehension, knowledge, application, analysis/synthesis and evaluation) . The instruments were administered under strict examination condition to the respondents in their various schools by the researcher and some Mathematics teachers in the sampled schools also helped in the supervision of the examinees. The instruments were administered on 30 SSS III students from each school with 10 students selected from each class (Science, Commercial and Arts). The test was administered using the Optical Mark Recorder (OMR) answer sheets; instructions on how to answer questions on the provided objective test answer sheet were given to the respondents. After administering and retrieving the instruments from the examinees, the researcher scored the items according to a prepared scoring key. The correct option was scored " 1 " while the incorrect option was scored " 0 ". The instruments were administered under strict examination conditions as given by the examination bodies. The test time duration was one hour and thirty minutes. The data collected from the administered 2015 Mathematics Achievement Test "A" and "B" were analyzed. The psychometrics properties of the test items were determined (i.e. item difficulty and item discrimination)

\section{Results}

Research Question 1: What are the item parameters of the Ekiti State Unified Mathematics Examination?

Students' responses to items of Unified Mathematics Examination were scored for each item. Based on students' performance on each of the items, an item analysis was carried out with the use of SPSS version 20 to establish the difficulty index and discrimination power of each of the items. The results were as presented in Table .1

Table 1: Item parameters of Ekiti State Unified Mathematics Examination

\begin{tabular}{|c|c|c|c|c|c|}
\hline Items & Difficulty Index & Discrimination Index & Items & Difficulty Index & Discrimination Index \\
\hline$\overline{\mathrm{Q} 1}$ & 41.75 & -.173 & Q26 & 19.59 & .218 \\
\hline Q2 & 20.10 & .029 & Q27 & 42.27 & .443 \\
\hline Q3 & 35.05 & .276 & Q28 & 21.65 & .223 \\
\hline Q4 & 46.39 & .409 & Q29 & 22.68 & .053 \\
\hline Q5 & 35.57 & .143 & Q30 & 16.49 & .122 \\
\hline Q6 & 39.69 & .169 & Q31 & 27.84 & .258 \\
\hline Q7 & 18.04 & .126 & Q32 & 28.35 & .261 \\
\hline Q8 & 22.16 & .090 & Q33 & 27.32 & .201 \\
\hline Q9 & 26.80 & .445 & Q34 & 41.24 & -.001 \\
\hline Q10 & 19.07 & .285 & Q35 & 40.72 & .268 \\
\hline Q11 & 11.34 & -.112 & Q36 & 31.96 & .154 \\
\hline Q12 & 31.44 & .472 & Q37 & 27.84 & .222 \\
\hline Q13 & 24.74 & .389 & Q38 & 38.66 & -.014 \\
\hline Q14 & 37.63 & .339 & Q39 & 26.29 & .301 \\
\hline Q15 & 38.66 & .232 & Q40 & 29.38 & .457 \\
\hline Q16 & 37.11 & .624 & Q41 & 21.13 & .183 \\
\hline Q17 & 41.75 & .259 & Q42 & 29.90 & .304 \\
\hline Q18 & 28.87 & .189 & Q43 & 36.08 & .301 \\
\hline Q19 & 40.72 & .475 & Q44 & 50.00 & .388 \\
\hline Q20 & 34.02 & .115 & Q45 & 23.20 & .304 \\
\hline Q21 & 30.93 & .548 & Q46 & 42.27 & .143 \\
\hline Q22 & 29.38 & .085 & Q47 & 34.54 & .199 \\
\hline Q23 & 34.02 & .161 & Q48 & 36.08 & .305 \\
\hline Q24 & 17.01 & .038 & Q49 & 46.39 & .293 \\
\hline Q25 & 34.02 & .072 & Q50 & 23.71 & .244 \\
\hline Average & & & & 31.24 & .2303 \\
\hline
\end{tabular}


Table 1 showed that the item difficulty index of the Ekiti State Unified mathematics examination ranged between $11.34 \%$ and $50.0 \%$ while the discrimination index ranged between -0.001 and .624 . The range of difficulty index presented in Table 1 using conventional interpretation (75\% to $100 \%$ - Easy, $26 \%$ to $74 \%$ moderate and $0 \%$ to $25 \%$ - Hard) showed that the item difficulty indices ranged between 'hard' and 'moderate'. Also the range of discrimination index using conventional interpretation $(0.30$ and above - Good, 0.10 to 0.29 - Fair, 0 - no discrimination and less than 0 - poor) showed that the item discrimination indices were from 'poor to 'good'. Table .1 also showed that the average test difficulty and discrimination index of the State unified Mathematics examination were 0.3124 and 0.2303 respectively. This indicated that the State Unified Mathematics Examination was generally of moderately difficulty and it fairly discriminated among the students. Further analysis was carried out on the distribution of the item difficulty and discrimination. Conventional interpretation were used and the results showed that $28 \%$ of the Unified Mathematics examination were very difficult for the students, $72 \%$ of the items were moderately difficult and $34 \%$ of the items discriminated very well while $58 \%$ fairly discriminated and $8 \%$ of the items did not discriminate among the students (see Table .2).

Table 2: Distribution of the Ekiti State Unified Mathematics Examination items on difficulty and discrimination interpretation

\begin{tabular}{llll}
\hline & Item Interpretation & Frequency & Percent \\
\hline \multirow{3}{*}{ Difficulty Index } & Hard & 14 & 28.0 \\
& Moderate & 36 & 72.0 \\
& Total & 50 & 100.0 \\
& No Disc & 4 & 8.0 \\
Discrimination & Fair & 29 & 58.0 \\
Index & Good & 17 & 34.0 \\
& Total & 50 & 100.0 \\
\hline
\end{tabular}

Research Question 2: What are the item parameters of WASC Mathematics Examination?

Students' responses to items of the WASC Mathematics Examination were scored, and item analysis was carried out to establish the difficulty index of each of the items. The results were as presented in Table 3

Table 3: Item parameters of WASCE Mathematics Examination

\begin{tabular}{|c|c|c|c|c|c|}
\hline Items & Difficulty Index & Discrimination Index & Items & Difficulty Index & $\begin{array}{l}\text { Discrimination } \\
\text { Index }\end{array}$ \\
\hline$\overline{\mathrm{Q} 1}$ & 55.67 & .484 & Q26 & 40.72 & .879 \\
\hline Q2 & 64.43 & .474 & Q27 & 41.75 & .788 \\
\hline Q3 & 60.82 & .537 & Q28 & 31.96 & .681 \\
\hline Q4 & 39.18 & .344 & Q29 & 45.36 & .871 \\
\hline Q5 & 46.91 & .694 & Q30 & 40.21 & .732 \\
\hline Q6 & 29.90 & .363 & Q31 & 39.18 & .849 \\
\hline Q7 & 34.54 & .442 & Q32 & 45.88 & .824 \\
\hline Q8 & 52.58 & .592 & Q33 & 48.45 & .817 \\
\hline Q9 & 57.22 & .559 & Q34 & 47.94 & .832 \\
\hline Q10 & 43.81 & .705 & Q35 & 54.12 & .693 \\
\hline Q11 & 53.61 & .585 & Q36 & 44.85 & .764 \\
\hline Q12 & 45.88 & .809 & Q37 & 38.66 & .776 \\
\hline Q13 & 47.94 & .737 & Q38 & 42.78 & .737 \\
\hline Q14 & 61.34 & .517 & Q39 & 38.66 & .835 \\
\hline Q15 & 43.81 & .861 & Q40 & 42.27 & .813 \\
\hline Q16 & 41.24 & .845 & Q41 & 44.85 & .739 \\
\hline Q17 & 43.81 & .773 & Q42 & 48.45 & .855 \\
\hline Q18 & 48.45 & .828 & Q43 & 39.69 & .812 \\
\hline Q19 & 43.81 & .831 & Q44 & 46.91 & .835 \\
\hline Q20 & 46.91 & .819 & Q45 & 41.75 & .844 \\
\hline Q21 & 42.27 & .876 & Q46 & 41.75 & .638 \\
\hline Q22 & 47.94 & .792 & Q47 & 44.85 & .778 \\
\hline Q23 & 44.33 & .780 & Q48 & 40.21 & .860 \\
\hline Q24 & 39.69 & .812 & Q49 & 46.91 & .876 \\
\hline Q25 & 39.18 & .831 & Q50 & 43.30 & .885 \\
\hline Average & & & & 45.13 & .7381 \\
\hline
\end{tabular}


Table 3 showed that the item difficulty index of the WASC Mathematics Examination ranged between $29.9 \%$ and $64.4 \%$ while the discrimination index ranged between 0.344 and 0.885 . The range of difficulty index using conventional interpretation ( $75 \%$ to $100 \%$ - Easy, $26 \%$ to $74 \%$ moderate and $0 \%$ to $25 \%$ - Hard) showed that the item difficulty index was 'moderate'. The result also showed that with the use of conventional interpretation of discrimination index ( 0.30 and above - Good, 0.10 to 0.29 - Fair, 0 - no discrimination and less than 0 - poor), the item discrimination index of the WAEC Mathematics Examination was 'good'. The average test difficulty and discrimination index of the State Unified Mathematics examination were $45.13 \%$ and 0.7381 respectively, the WAEC Mathematics Examination was moderately difficult and discriminated very well among the students.

Research Question 3: How comparable are the two mathematics examinations items in terms of examinee's scores and item parameter using test score equating?

In order to establish the equivalence of WAEC and UNIFIED examinations, examinees' test scores on the two forms of test were compared, the descriptive statistics of the test scores were on Table 4.

Table 4: Descriptive statistics of 50-item PAT and 2014 WAEC-POP

\begin{tabular}{lllll}
\hline & Mean & Sd & Min & Max \\
\hline WAEC(x) & 22.57 & 18.55 & 0 & 50 \\
UNIFIED $(y)$ & 15.62 & 6.96 & 13 & 30 \\
\hline
\end{tabular}

Table 4 show the descriptive statistics of the test scores of the examinees on WAEC and UNIFIED tests. From Table 4 , it was revealed that WAEC test was more difficult $(\mathrm{M}=22.57 ; \mathrm{Sd}=15.65)$ than the UNIFIED test $(\mathrm{M}=$ 15.62; $\mathrm{Sd}=6.96)$. Thus, to assess the equivalent scores of the tests, the test scores emanating from the tests were linked. The WAEC test scores were transformed to the scale of UNIFIED test using linear equating. According to Kolen and Brennan (2014), linear equating is represented by

$m_{y}(x)=y=\frac{\sigma(Y)}{\sigma(X)} x+\left[\mu(Y)-\frac{\sigma(Y)}{\sigma(X)} \mu(X)\right]----------\quad$ Equation 1

Where $\frac{\sigma(Y)}{\sigma(X)}=$ Slope usually represented with A

$\mu(Y)-\frac{\sigma(Y)}{\sigma(X)} \mu(X)=$ Intercept, usually represented with B

On substitution equation 1 becomes

$m_{y}(x)=y=A x+B$

Equation 2

This was achieved using equate package of $\mathrm{R}$ language and Environment for statistical computing. The results are presented as illustrated in Table 5

Table 5: slope and intercept of the linking

\begin{tabular}{ll}
\hline Slope & Intercept \\
\hline 7.1471 & 0.3754 \\
\hline
\end{tabular}

On substitution for slope and intercept in equation 2 we have

$$
m_{\text {unified }}(W A E C)=U N I F I E D=7.1471 \text { WAECSCORE }+0.3754
$$

Thus the equating function used in placing WAEC scores on the scale of UNIFIED test for effective comparison of the test scores form the two tests. The WAEC and UNIFIED test equivalent using the equating function revealed that:-

WAEC scores of $0,1,2,3,4,5,6,7,8,9,10,11,12,13,14,15,16,17,18,19,20,21,22,23,24,25,26,27,28$, $29,30,31,32,33,34,35,36,37,38,39,40,41,42,43,44,45,46,47,48,49$ and 50 were equivalent of:- 7.15, $7.52,7.90,8.27,8.65,9.02,9.40,9.77,10.15,10.53,10.90,11.28,11.65,12.03,12.40,12.78,13.15,13.53,13.90$, $14.28,14.65,15.03,15.41,15.78,16.16,16.53,16.91,17.28,17.66,18.03,18.41,18.78,19.16,19.54,19.91$, $20.29,20.66,21.04,21.41,21.79,22.16,22.54,22.91,23.29,23.66,24.04,24.42,24.79,25.17,25.54$ and 25.92 of UNIFIED scores respectively

Hypothesis 1: The difference in students' performance in the State Unified and the WAEC conducted Mathematics Examinations is not significant

To test this hypothesis, students' score in both Mathematics Examinations were compared using the paired sample t-test statistic and the result is as presented in Table 6 
Table 6: Difference in the performance of students in the State Unified and the WAEC mathematics items

\begin{tabular}{llllllll}
\hline Examination & $\mathrm{N}$ & $\bar{X}$ & $\mathrm{Sd}$ & $\mathrm{r}$ & $\mathrm{t}$ & $\mathrm{Df}$ & $\mathrm{sig}$ \\
\hline WASCE & 360 & 18.8111 & 14.29759 & \multirow{2}{*}{0.173} & 4.664 & \multirow{2}{*}{359} & 0.000 \\
Unified Examination 360 & 15.2833 & 5.25482 & & & & \\
\hline
\end{tabular}

The result presented in Table 6 showed that students' class average performance in the two examinations was 18.81 and 15.28 for WAEC and the State Unified Examination respectively. The $t$-test value $(t=4.664, \mathrm{p}<0.05)$ showed that the difference in the performance was significant and with Pearson Product Moment Coefficient $(\mathrm{r}=$ $0.173, \mathrm{p}=0.001$ ), the difference in students' performance in the two examinations was significant.

Hypothesis 2: Students' performance in the State Unified mathematics examination will not significantly predict their success in the WASCE Mathematics examination.Students' scores in both examinations were analysed with the use of linear regression. Scores in the State Unified Examination was used as the independent variable to predict scores in the WAEC Mathematics that served as the dependent variable. The result is presented on Table 7

Table 7: Regression analysis predicting students success in the WASCE

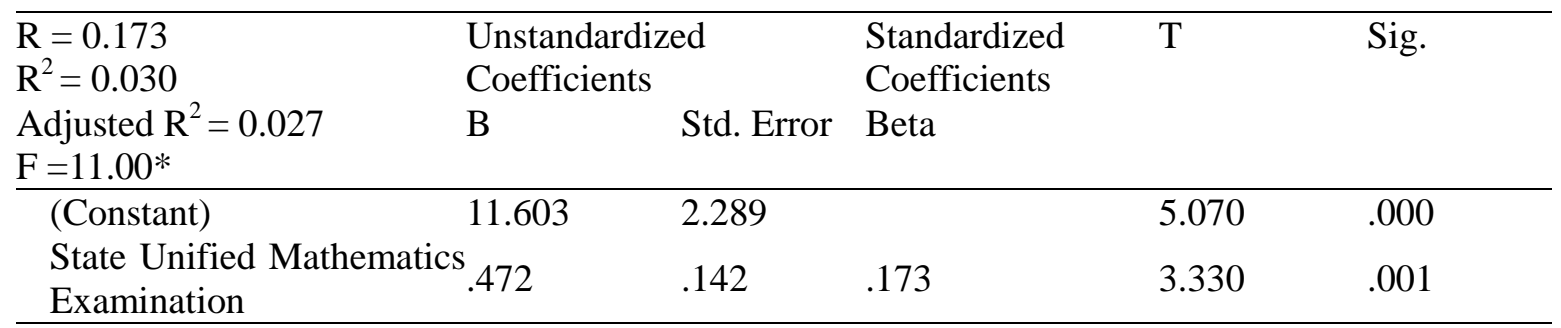

a. Dependent Variable: State Unified Exam Score

The result on Table 7 showed that $\mathrm{R}^{2}=0.030$ which indicated that only $3 \%$ of the variance in students' performance in the WAEC Mathematics Examination could be explained by the regression model. In other words, the success of a student in WAEC Mathematics examination related to their performance in State Unified Mathematics Examination. With the F-ratio value $(\mathrm{F}=11.00, \mathrm{p}=0.000)$, the regression model explains a statistically significant proportion of the variance and predicts WAEC mathematics success accurately. The regression coefficient $(\beta=0.472)$ as shown on Table 7 indicated that for every unit increase in students' performance in the State Unified Mathematics Examination the model predicted an increase of 47.2\% in students' score in the WAEC Mathematics Examination. Thus the regression equation can be represented with the equation WAEC Score $=11.603+(0.472)$ Unified exam score. Finally with the $t$-tests value $(t=3.330, p=0.001)$ at 0.05 level of significant students' performance in the State Unified Mathematics Examination made a statistically significant contribution to students' success in the WAEC Mathematics Examination.

\section{Discussion}

From the analysis carried out on this study, the results of research question one showed that the item difficulty index of the Ekiti State Unified Examination (ESUE) Mathematics items ranged between 'hard' and 'moderate'. The level of difficulty of items was the proportion of the number of students who answered a question correctly by the total number of students who took the test. It was shown that the ESUE Mathematics items were generally moderately difficult, these could be expressed as good items because they tested not too difficult or too easy. The result showed that the items in the ESUE Mathematics categorized as hard amounted to 14 items (28\%) and moderate amounted to 36 items (72\%) using convention interpretation. There were no easy items. This result was in line with Dian (2015) who conducted a research on test item analysis of the final examination of Economics subject in Grade xii Banyumas academic year 2014/2015. Based on the results, it was obtained that the number of multiple choice questions categorized as hard questions amounted to 11 items (31.4\%), medium category 19 items $(52.3 \%)$, and easy category 5items. This showed that the questions were moderately difficult. Also this finding conformed to the opinion of Anas (2006) who stated that the good item was the item that was not too difficult and not too easy. Therefore items in the category of moderate could be included into question banks for re-use as an evaluation in the future. Items that were easy or difficult should be re-examined to determine the cause of why they were easy or difficult, so that they could be revised and tested on the next test. 
Research question two showed that the item difficulty index of the WASCE mathematics items ranged between $29.9 \%$ and $64.4 \%$. (100\% to $75 \%$-easy, $74 \%$ to $26 \%$-medium, $25 \%$ to $0 \%$ - hard). From the range of the item difficulty index, it was moderate i.e. the mathematics items were moderately difficult. A research conducted by Olutola (2015) on the item difficulty and discrimination indices of SSCE multiple choice Biology test used by WAEC and NECO in Nigeria showed that the difficulty index of the WASCE multiple choice Biology test was moderately difficult with the ranges of $(100 \%$ to $70 \%$-easy, $69 \%$ to $30 \%$-moderately difficult and $29 \%$ to $0 \%$ hard). The item difficulty index ranged between $28.2 \%$ and 53.0\%). It was found that the 2008 WAEC Biology items were moderately difficult.

Discrimination index is the ability of items to distinguish participants from the highest to the lowest group, it was revealed that the item discrimination index of ESUE Mathematics items ranged between -0.001 and 0.624 which implied that it ranged from 'poor' to 'good'. Conventional interpretation of distinguishing power was from 0.30 and above and was included in the category of good, 0.10 to 0.29 was included in fair, and 0 - no discrimination and less than 0 was included in the poor category. The result showed that the ESUE Mathematics items with good distinguishing power totaled 17 items(34\%), fairly discriminating power amounted to 29 items (58\%) and 4 items (8\%) did not discriminate at all among the students. The findings implied that the ESUE Mathematics items were able to flutter between a high group students and low group. The result conformed the findings of Sudijono (2011) that the item discrimination index of the WASCE Mathematics items was 'good', the average discrimination index was 0.7381 , which implied that it was positive, strong and it discriminated very well among the students. Related research conducted by Olutola (2015) on item discrimination indices of the SSCE Multiple choice Biology test used by WAEC and NECO revealed that the discrimination index of WASCE Biology items could be said to be good. The results of research question three showed that the WAEC scores is equivalent to the Unified scores using linear equating method. Related research conducted by Adewale (2015) where he equated BECE of 2013 and 2014 revealed that the scores from the two examinations were very close. The study also corroborated that of Olatunji (2015) where linear method was used to equate scores of NECO and WAEC

The first hypothesis showed that students class average performance in the both WAEC and Unified were 18.81 and 15.28 respectively. Thet-test value $(\mathrm{t}-4.664, \mathrm{p}<0.05)$ showed that the difference in the performance was significant and with Pearson Product Moment Coefficient $(\mathrm{r}=0, \mathrm{p}=0.001)$, the difference in students' performance in the WAEC and ESUE were significant. It was positive, reflecting the fact that each case of the two variables were positively related and strong. Hypothesis two showed students' performance in the ESUE Unified Mathematics would significantly predict the success in the WASCE Mathematics $\left(R^{2}=0.030\right.$. Therefore, scores of the Unified Examination in Ekiti state could be used to equate the scores of the WASCE.

\section{Conclusion}

The study therefore concluded that Mathematics items of the Ekiti State Unified Examination and the WAEC are administering is equivalent. The scores yielded from the State Unified items and the WAEC items are symmetry; that both difficulty index and discriminating power of the two test items are significantly different. Also the result of the analysis revealed further that for every unit increase in student's performance in the State Unified Mathematics Examination, the model predicts an increase of $47.2 \%$ in student's score in WAEC Mathematics Examination. Therefore, students' performance in the State Unified Mathematics Examination made a statistically significant contribution to students' scores in the WAEC Mathematics Examination.

\section{References}

Adewale J. G. (2015) Equating two Year BECE Results in Basic Science and Technology in Oyo State, Nigeria. International Centre for Educational Evaluation (ICEE) Institute of Education,University of Ibadan - Nigeria

Kolen, M .J., \& Brennan, R.L. (2004). Testing Equating, Scaling, and Linking Methods and Practices. New York: SpringVerlag

Olatunji, D. S. (2015). Analysis of Linear and Equipercentile Equating Of Senior School Certificate Examination Economics Multiple-Choice Papers in Kwara State, Nigeria. Unpublished Ph.D. Thesis, University of Ilorin.

Onukwo, G.I.N. (2002). Fundamentals of educational measurement and evaluation. Cape Publishers International: Owerri, Imo State.

Osokoya, M. M. (2013). A Comparative Anallysis of West Africa Examinations Council,National Examinations Council and Joint Admissions and Matriculation Board Chemistry Tests. Nigerian Journal of Educational Research and Evaluation Vol. 12, 83-95. 